\title{
Failure of High-Flow Nasal Cannula and Non-invasive Ventilation Can Be Associated with Increased Risk of Mortality and Morbidity in Critically III Children
}

\section{Fatih AYGUN ( $\sim$ faygun9@hotmail.com)}

İstanbul Üniversitesi Cerrahpaşa Tıp Fakültesi https://orcid.org/0000-0001-6519-6583

\section{CANSU DURAK}

Istanbul Universitesi-Cerrahpasa Cerrahpasa Tip Fakultesi

\section{Fatih VAROL}

Istanbul Universitesi-Cerrahpasa Cerrahpasa Tip Fakultesi

\section{Alper KACAR}

Turkiye Cumhuriyeti Saglik Bakanligi Okmeydani Egitim ve Arastirma Hastanesi

\section{Emre AYGUN}

Turkiye Cumhuriyeti Saglik Bakanligi Okmeydani Egitim ve Arastirma Hastanesi

\section{Ahmet IRDEM}

Turkiye Cumhuriyeti Saglik Bakanligi Okmeydani Egitim ve Arastirma Hastanesi

\section{Haluk ÇOKUĞRAŞ}

Istanbul Universitesi-Cerrahpasa Cerrahpasa Tip Fakultesi

\section{YILDIZ CAMCIOĞLU}

Istanbul Universitesi-Cerrahpasa Cerrahpasa Tip Fakultesi

\section{Halit CAM}

Istanbul Universitesi-Cerrahpasa Cerrahpasa Tip Fakultesi

\section{Research article}

Keywords: Respiratory failure, non-invasive ventilation, pediatric intensive care unit, mortality

Posted Date: August 24th, 2019

DOl: https://doi.org/10.21203/rs.2.13540/v1

License: (a) (i) This work is licensed under a Creative Commons Attribution 4.0 International License. Read Full License 


\section{Abstract}

Background: This retrospective study aimed to describe the efficacy, complications, and outcome of noninvasive mechanical ventilation (NIV) in critically ill children. Non-invasive mechanical ventilation (NIV) has achieved a significant breakthrough success in treating acute respiratory failure. NIV failure drastically increases the risk of mortality and morbidity. Many factors have been associated with the success of NIV. Methods. We performed a multicenter retrospective study using the demographic, prognostic, and laboratory findings of children ( $<18$ years old) who were admitted in two pediatric intensive care units (PICUs). We compared clinical and laboratory variables in both successful and failed NIV groups. Results. Between January 2014 and April 2019, 1101 children were admitted to two PICU wards, of which, 403 were eligible for this study. In total, 138 (34.2\%) patients received high-flow nasal cannula (HFNC), 138 (34.2\%) patients received NIV-pressure control and 127 (31.6\%) received NIV-pressure support (PSV). Patient mortality was $3.2 \%$ (13 patients) and the success rate of our study was $83.4 \%$. Majority of our patients were provided NIV on admission (62.8\%). Patients with successful NIV required fewer inotropic drugs, had shorter PICU stay duration, and a lower mortality rate during the follow up. The failure group presented a greater frequency of NIV-PSV and NIV-PCV use, along with higher NIV-associated complications. Logistic regression analysis revealed that NIV and HFNC failure increased PICU mortality by 19 times. Conclusions. HFNC and NIV are support modalities for respiratory distress in the PICU and were associated with a significant decrease in the PICU intubation rate.

\section{Background}

Mechanical ventilation is one of the most important components of modern intensive care practice and is one of the most common reasons of intensive care admissions [1]. In the last 20 years, non-invasive mechanical ventilation (NIV) has undergone significant breakthrough improvement to treat acute respiratory failure [2]. It can successfully reduce the need for invasive mechanical ventilation, decrease respiratory workload, and improve gas exchange and oxygenation $[3,4]$. The primary advantage of NIV is providing an effective ventilation without involving the complications associated with endotracheal intubation. Additionally, NIV preserves airway defense mechanisms, speech, and swallowing in patients [5]. Previous studies report it to be a successful alternative to treat children with bronchiolitis, post-extubation respiratory failure, pneumonia, pulmonary edema, and status asthmaticus [4].

NIV failure drastically increases the risk of mortality and morbidity [6]. Several factors have been associated with its success in treating pediatric patients such as a careful patient selection, correct timing, an experienced pediatric intensive care unit (PICU) team, or an appropriate and comfortable interface [4, 7]. Only a small number of studies evaluate the relationship between the success of NIV and the outcomes of its use in critically ill children. Additionally, we have not yet determined the most appropriate and effective NIV technique in the PICU. We aimed to examine the efficacy, complications, and outcome of NIV in the critically ill children.

\section{Methods}


Healthcare was provided to children aged $<18$ years in two pediatric intensive care units (PICUs). The first was equipped with 7 beds, 7 ventilators, 2 isolation rooms, and 2 high flow machines. The second center was a tertiary, multidisciplinary PICU located in a training and research hospital in Istanbul, Turkey, having 12 beds, 2 isolation rooms, 10 ventilators, and 5 high flow machines. The patient data admitted to the PICUs from January, 2014 to April, 2019 were extracted from both electronic and written medical records (conforming to the ethical principles for medical research), and we included patients who received NIV in this study (Figure 1).

We excluded the patients with a history of a PICU stay lasting less than $24 \mathrm{~h}$, who died on the first day of admission, and with incomplete data. Ethical approval with waiver of consent was obtained from each institution that approved the study (İstanbul University-Cerrahpaşa, ethical committee no. 29430533-903.9992611, December 2018, and Okmeydani Research and Training Hospital, ethical committee no. 07.11.2017755). All clinical investigations were conducted according to the principles expressed in the Declaration of Helsinki of 1975, revised in 2013 [8].

We recorded all materials, data, computer codes, and protocols associated with the publication for readers.

Patient Population and Data Collection

The patients' sex, age, diagnosis at admission, duration of NIV, pediatric risk of mortality (PRISM-III) score, duration of intensive care unit stays, NIV modes, NIV outcome, NIV timing, and mortality were investigated (Table I).

We divided the patients three groups according to NIV types as HFNC, PCV, and PSV and compared their prognostic and laboratory results. The first NIV was included in the study (Table II).

We compared clinical and laboratory variables for both successful and failed NIV groups (Table III).

NIV Devices and Equipment

We used Maquet Servo-i ${ }^{\circledR}$ and Servo-u ${ }^{\circledR}$ (Maquet Critical Care, Solna, Sweden) as ventilators, and AIRVO2 ${ }^{\circledR}$ (Fisher \& Paykel Healthcare, Auckland, New Zealand) as the nasal high-flow device. All ventilators of the first center were Servo-i ${ }^{\circledR}$. There were six Servo-i ${ }^{\circledR}$ and four Servo-u ${ }^{\circledR}$ in the second center. We covered the skin and the mask or the nasal cannula with wound dressing (Plus ulcer sheath, Comfeel, Coloplast ${ }^{\circledR}$; Peterborough, Cambridgeshire, UK). The MR850 (Fisher Paykel Healthcare, Auckland, New Zealand) was used as a humidifier in NIV patients with a ventilator. All patients were continuously monitored during NIV treatment. Oronasal masks were used during NIV-PCV and NIV-PSV, due to limited mask options.

Ventilation Strategy and Protocol

All patients were routinely sedated before the NIV with midazolam, dexmetadomidine, and ketamine, to control their agitation. The patients concurrently received ketamine with midazolam, to control its side effects. We used oro- or nasogastric catheters according to the patients' age in those receiving sedative infusions. A nasogastric tube was placed in all patients to avoid gastric distension or vomiting. We used NIVpressure support and control as the two modes of mechanical ventilation. We did not use NIV-CPAP 
(continuous positive airway pressure) in these patients. We used nasal cannulas in infants younger than 6 mo. An oronasal mask was preferred for infants older than 6 mo because of the increased air flow. The initial expiratory positive airway pressure was set according to the patient's respiratory failure between 6 and 12 $\mathrm{cmH}_{2} \mathrm{O}$, while we maintained an inspiratory positive airway pressure between 10 and $26 \mathrm{cmH}_{2} \mathrm{O}$ to obtain an exhaled tidal volume (TV) of $6-8 \mathrm{~mL} / \mathrm{kg}$ of the predicted body weight. The patients were intubated when the patients' respiratory workload did not decrease despite an increase in the total pressure requirement to values above $26 \mathrm{cmH}_{2} \mathrm{O}$. NIV parameters were readjusted according to $\mathrm{SpO}_{2}$, blood gases, ventilator parameters, and patients' clinic finds, after connecting NIV.

The flow rate for a high-flow nasal cannula (HFNC) was set to $2 \mathrm{~L} / \mathrm{kg} / \mathrm{min}$ at the beginning and subsequently changed according to the patient's needs $(5-50 \mathrm{~L} / \mathrm{min})$. The applied $\mathrm{FiO}_{2}$ was targeted to be kept at $50 \%$ or less. The patients were administered respiratory physiotherapy and facial pressure points massage every two hours. Patients were reconnected to the NIV after aspirating the mouth and nose, followed by the acquisition of blood gas samples in the second hour of NIV.

NIV failure criteria

Patients were intubated if the blood pH value was $<7.25, \mathrm{pCO}_{2}>65 \mathrm{mmHg}$, and $\mathrm{SpO}_{2}<85 \%\left(\mathrm{FiO}_{2}>80 \%\right)$ or no improvements in respiratory rate, Glasgow coma scale, and respiratory workload during NIV support. Additionally, hemodynamic or electrocardiographic instability, inability to protect the airways or to manage copious tracheal secretions were attributed to NIV failure. Intubation was accepted as a criterion for NIV failure. We only considered the first NIV record in patients receiving multiple NIV administrations. Neurally adjusted ventilatory assist (NAVA) patients were not included in the study. Patients who did not need NIV or intubation after 24 hours were considered successful.

Statistical Analysis

We used the IBM SPSS 21.0 (version 21.0; IBM Corp., Armonk, NY, USA) software to perform statistical analysis. Continuous and categorical data were expressed as median (range) and number (percentage), respectively. We compared the continuous variables using Student's t-test and Mann-Whitney U-test for parametric and non-parametric data, respectively. Categorical variables were compared using chi-squared test or Fisher's exact test. Univariate binary logistic regression models were used to calculate the relationship between risk factors and NIV failure reported as ORs and $95 \%$ Cis. For all tests, $p<0.05$ was considered to be statistically significant.

\section{Results}

Cohort flow

Of the 1101 children admitted to the PICUs, 588 patients were from the primary center and 513 from the secondary center. We included 403 for this study. Total 138 (34.2\%) patients received HFNC, 138 (34.2\%) received NIV-PCV and 127 (31.6\%) received NIV-PSV. Patient mortality was 3.2\% (13 patients) (Figure 1).

Demographics 
We selected 403 patients for the present study with 218 (54.1\%) boys and $185(45.9 \%)$ girls. Their ages were distributed between 1 month and 17.8 years, with a median of 1.0 year. The most frequent diagnosis at admission was primary respiratory disease (55.1\%), followed by neurologic or metabolic diseases $(17.1 \%)$. Respiratory system diseases were most commonly lower respiratory tract infections such as bacterial or viral pneumonia. The median duration of intensive care unit stay was 7.0 (from 1 to 122) days. Median NIV duration was 71.5 hours. Acute kidney injury (AKI) developed in 91 (24.8\%) patients while in PICU, and 50 $(12.4 \%)$ of these patients underwent continuous renal replacement therapy (CRRT), while others received supportive treatments. We treated 131 (32.5\%) patients with inotropic drugs. NIV success rate was $83.4 \%$. Majority of our patients received NIV on admission (62.8\%) (Table I).

Clinical and laboratory variables for the NIV types

There was no statistically significant difference in terms of sex, PRISM-III score, $\mathrm{AKI}, \mathrm{SpO}_{2}$ (starting to NIV), NIV duration, and diagnosis on admission between NIV types. There was a statistically significant relationship between age $(p \leq 0.001)$, red blood cell transfusion (RBC) $(p \leq 0.001)$, inotrope drugs need $(p=0.003)$, body temperature $(p=0.019)$, heart rate $(p=0.012)$, respiratory rate $(p=0.031)$, and duration of PICU stay $(p \leq 0.001)$. Calcium $(p \leq 0.001)$ and platelet count $(p=0.002)$ were statistically lower in the NIV-PS group. Successful NIV was higher in HFNC group $(p=0.008)$ (Table II).

Variables determining a successful or failed NIV

We noted a significant relationship between NIV failure and RBC transfusion $(p \leq 0.001)$, need for inotrope drugs $(p=0.002)$, duration of stay in PICU $(p \leq 0.001)$, duration of NIV $(p=0.040)$, and mortality $(p \leq 0.001)$. Lactate dehydrogenase $(L D H)(p=0.034)$ was statistically higher in the NIV-failure group. There was no significant difference between the successful and failed NIV groups' diagnosis on admission (Figure 2), along with the NIV timing and modes. Complications were statistically higher in the failure group (Table III).

Variables determining a successful or failed HFNC

HFNC failure was significantly correlated to PRISM III score ( $p=0.046), R B C$ transfusion $(p \leq 0.001)$, need for inotrope drugs $(p \leq 0.001)$, AKI $(p=0.005)$, duration of stay in PICU $(p \leq 0.001)$, and mortality $(p \leq 0.001)$. AST $(p \leq 0.001), L D H(p \leq 0.001)$, uric acid $(p \leq 0.001)$, and hemoglobin were statistically higher in the HFNC-failure group. The successful and failed HFNC groups did not show statistically significant differences for their diagnosis at admission, HFNC timing, and associated complications (Table IV).

Logistic regression analysis of the risk factors of NIV failure in the PICU

We calculated the ORs and relationship between risk factors and NIV failure via logistic regression models. The ORs were $9.568(\mathrm{Cl}, 3.831-23.896)$ for RBC transfusion, $3.371(\mathrm{Cl}, 1.712-6.637)$ for NIV timing, 2.840 (Cl, 1.411-5.718) for inotropic drug use, and 19.233 (Cl, 4.986-56.374) for mortality (Table V).

\section{Discussion}


Here, we report that NIV was effective and safe in treating respiratory failure in critically ill children, with only 13 patients dying post administration. Patients with successful NIV required fewer inotropic drugs, had shorter PICU stays, and lower mortality rates during the follow up. NIV-PSV and NIV-PCV were used more frequently in the failed groups. NIV associated complications were higher in the failure group.

in the last 20 years, NIV for critically ill infants and children has gradually increased, in providing non-invasive pressure support to the lungs during inspiration without endotracheal intubation. Endotracheal intubation is an invasive procedure involving a number of risks and negative consequences, including ventilatorassociated pneumonia and mechanical damage [9-11]. Additionally, NIV improves blood gas test results and reduces respiratory rate, frequency of intubation, length of hospital stay, and mortality $[10,11]$. Therefore, it is routinely practiced in PICUs. Recently, HFNC has been used as a respiratory support and several studies report its significant efficacy in infants [12,13]. In HFNC positive pressure is applied at the end of the expiration to avoid alveolar collapse, decreasing the effort of inspiration [14,15]. Additionally, TV is provided by the applied positive inspiratory pressure. Another advantage is the constant and higher $\mathrm{FiO}_{2}$ supported by NIV. Although HFNC cannot accomplish each component, positive airway pressure from the nasopharynx to the alveoli may simulate the effect of high flow [16].

Here, we used HFNC and NIV. Patients were selected based on their age and clinical condition. NIV-PSV and NIV-PCV were preferred in patients with concomitant chronic disease and organ failure (Table II). Although the HFNC group had a higher PRISM III score, they were not statistically correlated. Despite the high success rates of all three methods, that of HFNC was significantly higher, possibly due to the presence of concomitant diseases and organ failure. Furthermore, a recent retrospective study demonstrated that HFNC might be associated with lower post-cardiac surgery reintubation rates than NIV in children [17]. This difference was attributed to reduced dead space and respiratory workload. Contrarily, NIV increases dead space [17], requiring a more controlled ventilation, subsequently increasing the breathing workload.

A study previously reported that the presence of a chronic diseases affects outcomes of NIV administration [18]. Here, $44.9 \%$ of patients presented prior comorbidities, particularly neurologic or metabolic diseases. In the 50 neurological-metabolic sequelae patients from the NIV group, $14(28 \%)$ had failed NIV. Another pediatric study identified a higher failure rate among patients with a history of neurological diseases, attributed to pharyngeal hypotonia and poor airway protection [19]. However, here, the frequency of aspiration did not increase in the neurologic-metabolic patient group. The lower incidence of aspiration may be due to the insertion of a nasogastric catheter in these patients. Additionally, we did not feed patients first hours before decreasing work of breathing.

Several factors possibly affect the success or failure of NIV, such as the NIV indication, severity and type of the respiratory failure, the timing of NIV implementation; and the expertise of the health care team $[7,20]$. Follow-up was performed according to NIV protocol. Routine blood gas was taken at the second hour, and was monitored every 4 hours on the first day. Therefore, the success rates in the patients receiving NIV therapy in our study was similar to those observed literatures [6,20].

It has been reported that the first few hours of the NIV is crucial for its success [7, 13]; therefore, we carefully monitored the blood gas values along with the respiratory and cardiac signs. The blood gas control from the 
patients at the second hour were taken according to the NIV protocol. However, there was no relationship between NIV failure and the vital signs. Contrary to our study, previous studies demonstrate that respiratory rate [21], $\mathrm{SpO}_{2}$ (particularly $\mathrm{SpO}_{2} / \mathrm{FiO}_{2}$ ratio) [22], and heart rate during NIV usage were independent predictors of success.

In a prospective adult study showed that failure of NIV was associated with an increased risk of mortality and hospital stay [23]. In this study, patients that failed had higher rates of mortality. It was suggested that patients with higher mortality score would need closer monitoring during NIV. Another multicenter study involving a wider patient group, reported an increase in mortality with increase NIV failure rates [9], similar to the results of our study. Furthermore, 3 of the 5 HFNC patients who died were in the failed group, this group was also associated with significantly higher rates of organ failure and PRISM III score. Logistic regression analysis revealed that NIV and HFNC failure increased the PICU mortality 19 times in our study, indicating that this failure may be associated with more serious disease and mortality. Additionally, NIV failure patients also experienced higher rates of serious complications. Several studies have reported that NIV failure showed significant correlation with PRISM III score [24, 25], contrary to our NIV patients. However, our study reports a significant relationship between HFNC failure and PRISM III score.

Generally, NIV and HFNC are relatively safe strategies to treat respiratory failure in children. Complications include gastric distention, eye irritation, air leak (e.g. pneumothorax), and delayed intubation [26]. Here, the most serious complications were pneumothorax and aspiration of gastrointestinal contents. One of the three patients with pneumothorax was suffering from meningococcemia, the second from brain abscess and the third from Duchenne muscular dystrophy. Patient with meningococcemia subsequently died due to concomitant surgical wounds and nosocomial sepsis (Acinetobacter baumannii). The Duchenne muscular dystrophy patient underwent tracheostomy. Here, the most common complication was skin pressure lesions that have been reported in $4-27 \%$ of children in previous studies [28]. There was no severe skin necrosis.

Most studies do not recommend the use of sedatives, since the patients' agitation may be a manifestation of the significant hypoxia or the increased breathing strain [20]. Therefore, if sedation were to be performed, the drugs must not suppress the central respiratory drive and the protective airway reflexes [20,27]. After appropriate mask and trigger sensitivity adjustment, the patients were sedated with midazolam or ketamine. Dexmedetomidine, ketamine, and midazolam infusions were started in the patients presenting continued agitation. Ketamine infusion was particularly used in asthmatic patients. Our aim was to prevent asynchrony. The success of NIV and HFNC was similar to previous studies despite using sedatives [9, 22]. Therefore, low sedation doses do not adversely affect NIV success. However, the effect of sedation could not be evaluated in this study.

This study has a number of limitations, the first being that this was a retrospective and had limited number of patients. Concomitant medication, blood gas values, and sedation were not evaluated. Due to their observational nature, these results should be investigated further in randomized controlled trials. The strengths of our study are that the data was acquired from two centers, combination of HFNC and NIV, and the small number of similar studies in pediatric health. Additionally, our study included patients with varied characteristics and conditions. 


\section{Conclusions}

HFNC and NIV are support modalities for respiratory distress in the PICU, associated with a significant decrease in the PICU intubation rate. Therefore, their failure may have significant predictive value. Appropriately following protocols during NIV and HFNC treatments have fewer complications and higher success rates. Higher failure rates were observed in hematology-oncology patients, inotropic drug usage, and need for RBC transfusion than those with other comorbidities, suggesting the advantages of respiratory support.

\section{Abbreviations}

NIV: non-invasive mechanical ventilation; HFNC: High flow nasal cannula; PICU: Pediatric intensive care units; PRISM: pediatric risk of mortality score; CRRT: continuous renal replacement therapy; PCV: pressure control ventilation, PSV: pressure support ventilation; PRISM: pediatric risk of mortality score; AST: Aspartate Aminotransferase; LDH: Lactate dehydrogenase; AKI: Acute kidney injury.

\section{Declarations}

\section{Availability of data and materials}

The dataset and analyses are available from the authors.

\section{Competing interests}

The authors declare that they have no competing interests.

\section{Funding}

This research received no external funding.

\section{Acknowledgements}

None.

\section{Authors' contributions}

Conceptualization, F.A.; methodology, F.A. and A.K.; software, F.A. and E.A.; validation, F.A., H.Ç., and Y.C. and H.Ç.; formal analysis, F.A.; investigation, F.A.; resources, F.A.; data curation, F.A., F.V., and C.D.; writing-original draft preparation, F.A.; writing-review and editing, F.A., D.Y., A.I, and Y.C..; visualisation, F.A.; supervision, H.Ç., Y.C., and H.C.; project administration, F.A.; funding acquisition, F.A.".

\section{Consent for publication}

Not applicable. 


\section{Ethics approval and consent to participate}

Ethical approval with waiver of consent was obtained from each institution that approved the study (Istanbul University-Cerrahpaşa, ethical committee no. 29430533-903.99-92611, December 2018, and Okmeydani Research and Training Hospital, ethical committee no. 07.11.2017-755).

\section{References}

1. Meduri GU. Noninvasive ventilation. In: Marini J, Slutsky A (eds.). Physiological basis of ventilatory support: A series on lung biology in health and disease. Marcel Dekker, Inc., New York. pp. 921-998,1998.

2. Rocker GM, Mackenzie MG, Williams B, Logan PM. Noninvasive positive pressure ventilation: successful outcome in patients with acute lung injury/ARDS. Chest. 1999;115(1):173-177.

3. Carron M, Zarantonello F, Tellaroli P, Ori C. Perioperative noninvasive ventilation in obese patients: a qualitative review and meta-analysis. Surg Obes Relat Dis. 2016;12(3):681-691.

4. Demaret $P$, Mulder A, Loeckx I, Trippaerts $M$, Lebrun F. Non-invasive ventilation is useful in paediatric intensive care units if children are appropriately selected and carefully monitored. Acta Paediatr. 2015;104(9):861-871.

5. Argent AC, Biban P. What's new on NIV in the PICU: does everyone in respiratory failure require endotracheal intubation? Intensive Care Med. 2014;40(6):880-884.

6. Yaman A, Kendirli T, Ödek Ç, Ateş C, Taşyapar N, Güneş M. Efficacy of noninvasive mechanical ventilation in prevention of intubation and reintubation in the pediatric intensive care unit. J Crit Care. 2016;32:175-81.

7. Nava S, Hill N. Non-invasive ventilation in acute respiratory failure. Lancet. 2009;374 (9685):250-259.

8. Morris K. Revising the Declaration of Helsinki. Lancet. 2013;381(9881):1889-90.

9. Schnell D, Timsit JF, Darmon M, et al. Noninvasive mechanical ventilation in acute respiratory failure: trends in use and outcomes. Intensive Care Med. 2014;40:582-91.

10. Antonelli M, Conti G, Esquinas A, et al. A multiple-center survey on the use in clinical practice of noninvasive ventilation as a first-line intervention for acute respiratory distress syndrome. Crit Care Med. 2007;35:18-25.

11. Osadnik CR, Tee VS, Carson-Chahhoud KV, Picot J, Wedzicha JA, Smith BJ. Noninvasive ventilation for the management of acute hypercapnic respiratory failure due to exacerbation of chronic obstructive pulmonary disease. Cochrane Database Syst Rev. 2017;7:CD004104.

12. Kawaguchi A, Yasui Y, deCaen A, Garros D. The Clinical Impact of Heated Humidified High-Flow Nasal Cannula on Pediatric Respiratory Distress. Pediatr Crit Care Med. 2017;18(2):112-119

13. Schibler A, Pham TM, Dunster KR, et al. Reduced intubation rates for infants after introduction of highflow nasal prong oxygen delivery. Intensive Care Med 2011; 37:847-852.

14. Jaber S, Monnin M, Girard M, et al. Apnoeic oxygenation via high-flow nasal cannula oxygen combined with non-invasive ventilation preoxygenation for intubation in hypoxaemic patients in the intensive care unit: the single-centre, blinded, randomised controlled OPTINIV trial. Intensive Care Med. 2016; 42(12):1877-1887. 
15. Stéphan F, Barrucand B, Petit Pet al. High-Flow Nasal Oxygen vs Noninvasive Positive Airway Pressure in Hypoxemic Patients After Cardiothoracic Surgery: A Randomized Clinical Trial. JAMA. 2015; 313(23):2331-9.

16. Helviz Y and Einav S. A Systematic Review of the High-flow Nasal Cannula for Adult Patients. Crit Care. $2018 ; 22(1): 71$.

17. Shioji N, Kanazawa T, Iwasaki T, et al. High-flow Nasal Cannula Versus Noninvasive ventilation for Postextubation Acute Respiratory Failure after Pediatric Cardiac Surgery. Acta Med Okayama 2019;73(1):15-20.

18. Feudtner, C Feinstein JA, Zhong W, et al. Pediatric complex chronic conditions classification system version 2: updated for ICD-10 and complex medical technology dependence and transplantation. BMC Pediatr. 2014;14:199

19. Mayordomo-Colunga J, Medina A, Rey C, et al. Non invasive ventilation after extubation in paediatric patients: a preliminary study. BMC Pediatr 2010; 10:29.

20. Wolfler A, Calderini E, lannella E, et al. Evolution of noninvasive mechanical ventilation use: a cohort study among Italian PICUs. Pediatr Crit Care Med. 2015;16(5): 418-27.

21. James CS, Hallewell CP, James DP, Wade A, and Mok QQ. Predicting the success of non-invasive ventilation in preventing intubation and re-intubation in the paediatric intensive care unit. Intensive Care Med. 2011;37:1994-2001.

22. Mayordomo-Colunga J, Pons M, López Y, et al. Predicting non-invasive ventilation failure in children from the Sp02/FiO2 (SF) ratio. Intensive Care Med. 2013;39(6):1095-1103.

23. Corrêa TD, Sanches PR, de Morais LC, Scarin FC, Silva E, Barbas CS. Performance of noninvasive ventilation in acute respiratory failure in critically ill patients: a prospective, observational, cohort study. BMC Pulm Med. 2015; 15:144.

24. Mayordomo-Colunga J, Medina A, Rey C, et al. Predictive factors of non invasive ventilation failure in critically ill children: a prospective epidemiological study. Intensive Care Med. 2009;35(3):527-36.

25. Essouri S, Chevret L, Durand P, et al. Noninvasive positive pressure ventilation: five years of experience in a pediatric intensive care unit. Pediatr Crit CareMed. 2006;7(4):329-34.

26. Viscusi CD, Pacheco GS. Pediatric Emergency Noninvasive Ventilation. Emerg Med Clin North Am. 2018;36(2):387-400

27. Cavari Y, Sofer S, Rozovski U, et al. Noninvasive positive pressure ventilation in infants with respiratory failure. Pediatr Pulmonol. 2012;47(10):1019-25

28. Fedor KL. Noninvasive Respiratory Support in Infants and Children. Respir Care. 2017;62(6):699-717.

\section{Tables}

Table I. Demographic characteristics of NIV patients in the PICU. 


\begin{tabular}{|c|c|c|}
\hline \multicolumn{2}{|r|}{ Total number of patients $(n=403)$} & $\begin{array}{c}\mathrm{n}(\%) \text { or } \\
\text { median (Min-Max) }\end{array}$ \\
\hline \multicolumn{3}{|l|}{ Sex } \\
\hline - & Iale & $218(54.1 \%)$ \\
\hline • & emale & $185(45.9 \%)$ \\
\hline Age & & $1.00 \mathrm{y}(1 \mathrm{mo}-17.8 \mathrm{y})$ \\
\hline \multicolumn{3}{|c|}{ Intensive care hospitalization diagnosis } \\
\hline • & Respiratory disease & $222(55.1 \%)$ \\
\hline & Neurologic or metabolic disease & 69 (17.1\%) \\
\hline & Sepsis and septic shock & 48 (11.9\%) \\
\hline • & Cardiovascular disease & $25(6.2 \%)$ \\
\hline & Hematology-oncology patient & $18(4.5 \%)$ \\
\hline & Trauma & $6(1.5 \%)$ \\
\hline - & Other & $15(3.7 \%)$ \\
\hline \multicolumn{2}{|c|}{ Duration of stay in PICU (days) } & $7.0(1-122)$ \\
\hline \multicolumn{2}{|c|}{ Successful NIV } & $336(83.4 \%)$ \\
\hline \multicolumn{2}{|c|}{ Duration of NIV } & $71.5 \mathrm{~h}(2 \mathrm{~h}-144 \mathrm{~h})$ \\
\hline \multicolumn{2}{|c|}{ PRISM-III score } & $13.0(2-55)$ \\
\hline \multicolumn{2}{|c|}{ Acute kidney injury } & $91(22.6 \%)$ \\
\hline \multicolumn{2}{|l|}{ CRRT } & $50(12.4 \%)$ \\
\hline \multicolumn{2}{|c|}{ Inotrope drug usage } & $131(32.5 \%)$ \\
\hline \multicolumn{2}{|c|}{ Mortality } & $13(3.2 \%)$ \\
\hline \multicolumn{3}{|c|}{ NIV modes } \\
\hline \multirow[t]{3}{*}{ r } & High-flow nasal cannula & $138(34.2 \%)$ \\
\hline & NIV - pressure control ventilation & $138(34.2 \%)$ \\
\hline & NIV - pressure support ventilation & 127 (31.6\%) \\
\hline \multicolumn{3}{|c|}{ NIV timing } \\
\hline \multirow{2}{*}{\multicolumn{2}{|c|}{ - At the beginning }} & $253(62.8 \%)$ \\
\hline & & $150(37.2 \%)$ \\
\hline
\end{tabular}

NIV: noninvasive mechanical ventilation, PICU: pediatric intensive care unit, PRISM: pediatric risk of mortality score, CRRT: continuous renal replacement therapy

Table II. Clinical and laboratory variables for the NIV types. 


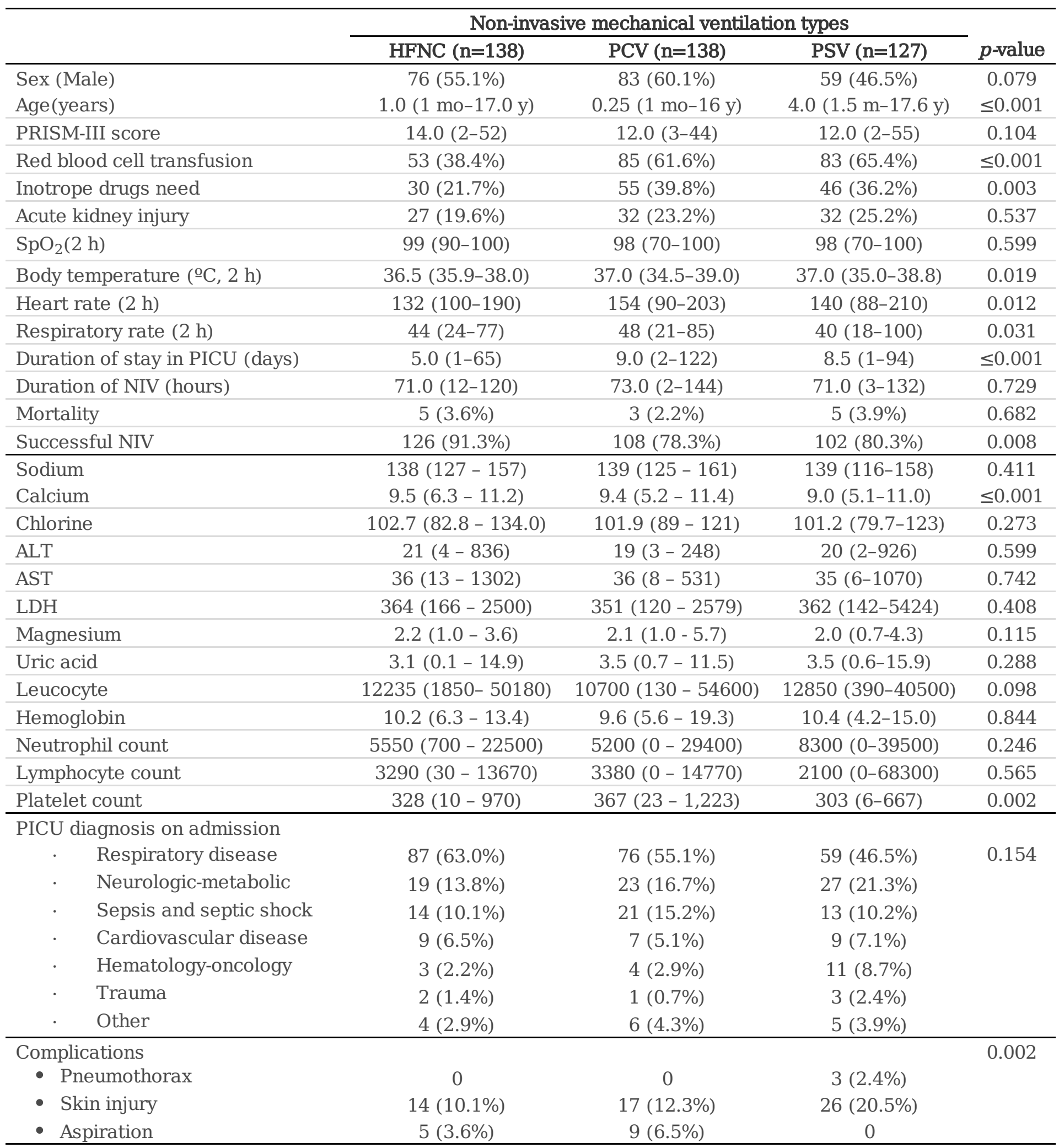

NIV: noninvasive mechanical ventilation, HFNC: high-flow nasal cannula, PCV: pressure control ventilation, PSV: pressure support ventilation, PICU: PRISM: pediatric risk of mortality score, pediatric intensive care unit, ALT: Alanine aminotransferase, AST: Aspartate Aminotransferase, LDH: Lactate dehydrogenase.

Table III. Clinical and laboratory variables for the successful and failed NIV usage patients. 


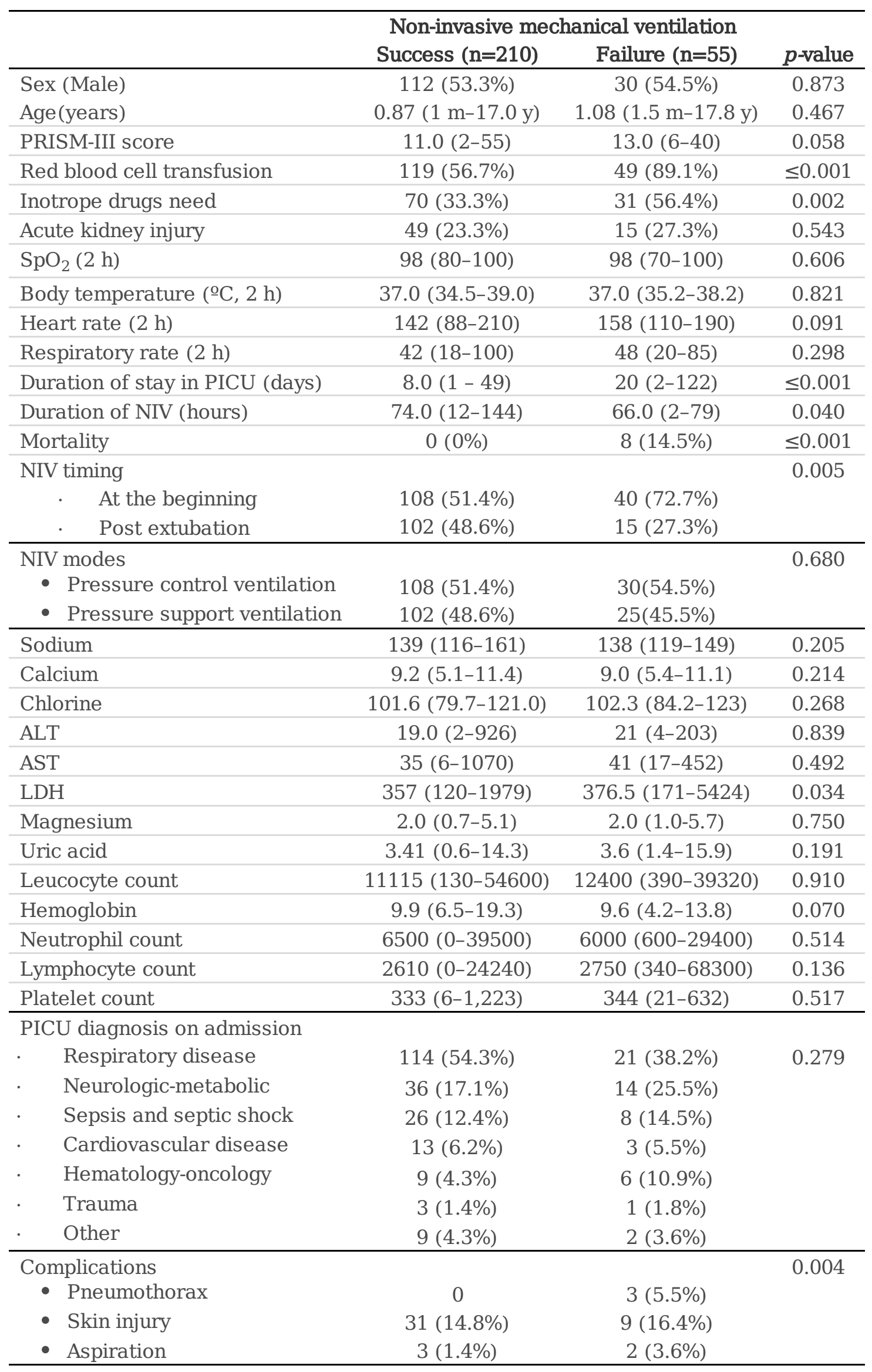

NIV: noninvasive mechanical ventilation, PRISM: pediatric risk of mortality score, PICU: pediatric intensive care unit, ALT: Alanine aminotransferase, AST: Aspartate Aminotransferase, LDH: Lactate dehydrogenase. 
Table IV. Clinical and laboratory variables for the successful and failed HFNC usage patients.

\begin{tabular}{|c|c|c|c|}
\hline & \multicolumn{2}{|c|}{ HFNC } & \multirow[b]{2}{*}{$p$-value } \\
\hline & Success $(n=126)$ & Failure $(n=12)$ & \\
\hline Sex (Male) & $69(54.8 \%)$ & $7(58.3 \%)$ & 0.812 \\
\hline Age(years) & $1.0(1 \mathrm{~m}-14.0 \mathrm{y})$ & $0.75(1.5 \mathrm{~m}-17.0 \mathrm{y})$ & 0.724 \\
\hline PRISM-III score & $11.0(2-52)$ & $15.5(7-41)$ & 0.046 \\
\hline Red blood cell transfusion & $43(34.1 \%)$ & $10(83.3 \%)$ & $\leq 0.001$ \\
\hline Inotrope drugs need & $20(15.9 \%)$ & $10(83.3 \%)$ & $\leq 0.001$ \\
\hline Acute kidney injury & $21(16.7 \%)$ & $6(50.0 \%)$ & 0.005 \\
\hline $\mathrm{SpO}_{2}(2 \mathrm{~h})$ & $99(90-100)$ & $96(94-98)$ & 0.744 \\
\hline Body temperature $\left({ }^{\circ} \mathrm{C}, 2 \mathrm{~h}\right)$ & $36.5(36.0-38.0)$ & $35.9(35.9-37.1)$ & 0.302 \\
\hline Heart rate $(2 \mathrm{~h})$ & $140(100-190)$ & $120(110-120)$ & 0.101 \\
\hline Respiratory rate (2 h) & $44(24-77)$ & $45(40-45)$ & 0.833 \\
\hline Duration of stay in PICU (days) & $5.0(1-59)$ & $19(10-65)$ & $\leq 0.001$ \\
\hline Duration of NIV (hours) & $45.0(12-120)$ & $28.0(2-30)$ & 0.177 \\
\hline Mortality & $2(1.6 \%)$ & $3(25.0 \%)$ & $\leq 0.001$ \\
\hline HFNC timing & & & 0.926 \\
\hline . At the beginning & $96(76.2 \%)$ & $9(75.0 \%)$ & \\
\hline . $\quad$ Post extubation & $30(23.8 \%)$ & $3(25.0 \%)$ & \\
\hline Sodium & 138 (127-157) & $139.5(127-147)$ & 0.436 \\
\hline Calcium & $9.5(6.3-11.2)$ & $9.5(7.5-10.2)$ & 0.114 \\
\hline Chlorine & $102.7(82.8-134.0)$ & $105.7(89.0-112.9)$ & 0.838 \\
\hline ALT & $21.0(4-836)$ & $43.0(9-272)$ & 0.100 \\
\hline AST & $34(13-1302)$ & $110.0(24-1015)$ & $\leq 0.001$ \\
\hline LDH & $359(166-1680)$ & $624.5(334-2500)$ & $\leq 0.001$ \\
\hline Magnesium & $2.22(1.00-3.60)$ & $1.95(1.22-2.58)$ & 0.073 \\
\hline Uric acid & $3.04(0.1-12.2)$ & $6.8(1.0-14.9)$ & $\leq 0.001$ \\
\hline Leucocyte count & $11650(1850-36960)$ & $14170(5600-50180)$ & 0.735 \\
\hline Hemoglobin & $10.2(6.3-13.4)$ & $7.0(6.5-11.1)$ & 0.012 \\
\hline Neutrophil count & $5400(700-22500)$ & $5900(5300-8200)$ & 0.620 \\
\hline Lymphocyte count & $3250(32-13670)$ & $4070(330-11300)$ & 0.073 \\
\hline Platelet count $\left(\times 10^{3} / \mathrm{mm}^{3}\right)$ & $339(42-970)$ & $248(10-553)$ & 0.167 \\
\hline \multicolumn{4}{|l|}{ PICU diagnosis on admission } \\
\hline Respiratory disease & $82(65.1 \%)$ & $5(41.7 \%)$ & 0.367 \\
\hline Neurologic-metabolic & $17(13.5 \%)$ & $2(16.7 \%)$ & \\
\hline Sepsis and septic shock & $12(9.5 \%)$ & $2(16.7 \%)$ & \\
\hline Cardiovascular disease & $7(5.6 \%)$ & $2(16.7 \%)$ & \\
\hline Hematology-oncology & $2(1.6 \%)$ & $1(8.3 \%)$ & \\
\hline Trauma & $2(1.6 \%)$ & $0(0 \%)$ & \\
\hline . $\quad$ Other & $4(3.2 \%)$ & $0(0 \%)$ & \\
\hline Complications & & & 0.270 \\
\hline - Pneumothorax & 0 & 0 & \\
\hline - Skin injury & 15 (11.9\%) & $2(16.7 \%)$ & \\
\hline - Aspiration & $7(5.6 \%)$ & $2(16.7 \%)$ & \\
\hline
\end{tabular}

high-flow nasal cannula, NIV: noninvasive mechanical ventilation, PRISM: pediatric risk of mortality score, PICU: ic intensive care unit, ALT: Alanine aminotransferase, AST: Aspartate Aminotransferase, LDH: Lactate 
Jgenase.

I. Logistic regression analysis of the risk factors of NIV and HFNC failure in the PICU

\begin{tabular}{lccc}
\hline RISK & $\boldsymbol{p}$ values & Odds Ratio & 95\% Confidence interval \\
\hline Sex & 0.516 & 0.812 & $0.432-1.524$ \\
NIV modes & 0.164 & 1.335 & $0.889-2.003$ \\
\hline Red blood cell transfusion & $\leq 0.001$ & 9.568 & $3.831-23.896$ \\
\hline Acute kidney injury & 0.106 & 1.916 & $0.864-4.566$ \\
\hline NIV timing & $\leq 0.001$ & 3.371 & $1.712-6.637$ \\
\hline Inotropic drug usage & 0.003 & 2.840 & $1.411-5.718$ \\
Mortality & $\leq 0.001$ & 19.233 & $4.986-56.374$ \\
\hline
\end{tabular}

NIV: noninvasive mechanical ventilation, HFNC: high-flow nasal cannula, PICU: pediatric intensive care unit

\section{Figures}




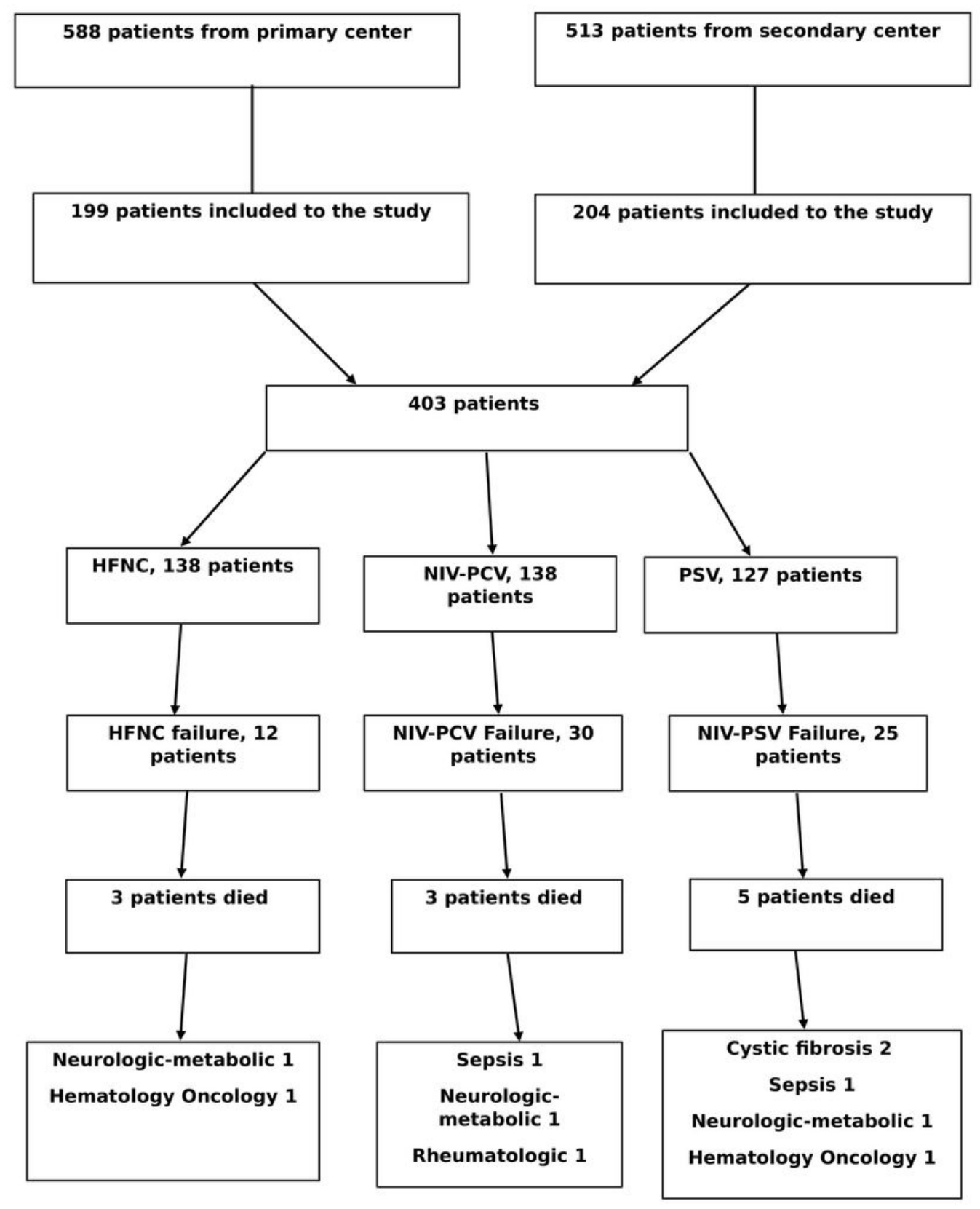

\section{Figure 1}

Cohort flow. 


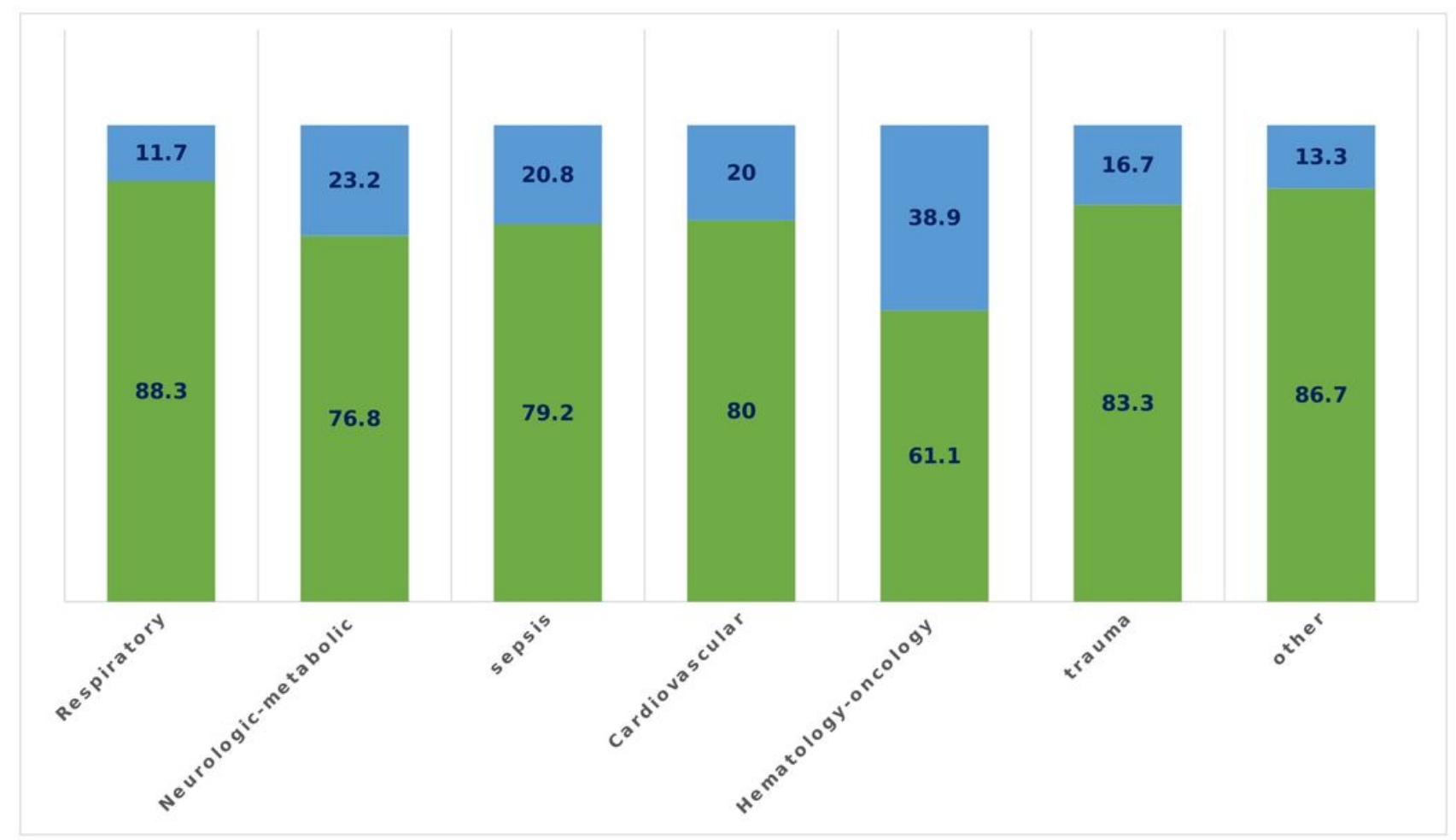

Figure 2

Percentage of success in the NIV patients according to diagnosis. 